\title{
Estimation of transport and degradation parameters for naphthalene and anthracene: influence of mass transfer on kinetics
}

\author{
Chiedu N. Owabor • Samuel E. Ogbeide • \\ Alfred A. Susu
}

Received: 20 November 2008 / Accepted: 9 October 2009 / Published online: 13 November 2009

(C) The Author(s) 2009. This article is published with open access at Springerlink.com

\begin{abstract}
The method of temporal moment solutions (MOM) for one-dimensional convectivedispersive solute transport involving linear equilibrium sorption and first-order degradation for time pulse sources has been applied to analyze experimental data from a soil microcosm reactor. Estimation of the pore water velocity $\mathrm{V}$ for a nonreactive solute was aided by the use of only the first normalized moment while the dispersion coefficient $D$, first-order degradation rate constant $\lambda$, and the retardation factor $R$ were estimated using both first and second normalized moments. These transport and degradation parameters were compared to those obtained by a transport model using a nonlinear least square curve-fitting program CXTFIT (version 2.0). Results obtained showed that the MOM fits the breakthrough curve with tailing better than the CXTFIT. The initial estimates of these parameters aided the reduction of the dimensionality of the search process of the nonsteady-state model. A residual concentration of
\end{abstract}

C. N. Owabor $(\varangle)$. S. E. Ogbeide

Department of Chemical Engineering,

University of Benin, Benin, Nigeria

e-mail: owabor4you@yahoo.com

A. A. Susu

Department of Chemical Engineering,

University of Lagos, Lagos, Nigeria
$1.12 \mathrm{E}-5$ and $1.48 \mathrm{mg} / \mathrm{l}$ for naphthalene and 7.67E-4 and $1.61 \mathrm{mg} / \mathrm{l}$ for anthracene, in the axial and radial directions, respectively, suggests the preference of naphthalene during the biodegradation process. The surface concentration as depicted using three-dimensional plots showed that there is occlusion of the aromatics (naphthalene and anthracene) within the soil micropores, thereby limiting their bioavailability and in the long run increasing their toxicity.

Keywords Normalized moments •

Surface concentration - Breakthrough curves • Biodegradation • Bioavailability

\section{Introduction}

Most of the interest in the biodegradation of polycyclic aromatic hydrocarbons (PAHs) in the field has been in the removal of the parent compounds, while most research on the pure cultures of PAHdegrading bacteria has focused on their ability to grow on or mineralize specific PAH substrates (Guo and Wagenet 1999; Vanderborght et al. 2000). Consequently, the bioremediation of PAH contamination with naturally occurring microorganisms has been attempted at a number of sites (Janikowski et al. 2004; Sudarat et al. 2000; Chung and King 2001). PAHs represent an important group of contaminants due to their carcinogenic 
effect. They are not particularly volatile, generally have poor water solubility, and have a distinct tendency to bind to organic substances. Although interactions among chemical components of a mixture undergoing biodegradation play an important role in determining the overall effectiveness of the process, interactions among microbial species in a mixed culture may also be significant (Oboh et al. 2006; Okerentugba and Ezeronye 2003).

The interplay between degradation and sorption has become significant as issues such as availability of subsurface contaminants for microbial degradation are explored. Mathematical models of mixed homologous substrates consumption and microbial growth abound (Gamerdinger et al. 1997; Reardon et al. 2002; Zhu et al. 2004).

This work has focused on the biodegradation of naphthalene and anthracene (a two- and threering PAHs). The work is aimed at characterizing the biodegradation process by considering the mass transfer limitations. Analytical solutions using the temporal moment solutions (MOM) described by Das and Kluitenberg (1996) and a nonlinear least square curve-fitting program, CXTFIT (version 2.0), as described by Toride et al. (1995) will be used to analyze and compare concentration breakthrough curves in the transport studies using experimental data from a soil microcosm reactor.

\section{Experimental}

One kilogram of unimpacted surface and subsurface soils contained in the microcosm reactor shown in Fig. 1 was spiked with a mixture of naphthalene and anthracene dispersed in 21 of water already containing $0.02 \%$ surfactant (sodium hexametaphosphate) and organization for economic cooperation and development nutrients (Tabak and Govind 1997). A separate experiment was set up and conducted without the contaminant solutes. This served as the control. Opening the valve at a constant flow rate ensured oxygen flow into the reactor. The temperature and pressure of the microcosm reactor was monitored throughout the experiment by means of a digital multimeter and a pressure gauge. Standard solvent extraction using $n$-hexane and dichloromethane (HPLC grade) and gas chromatography methods were used to determine the aqueous phase concentration of the contaminants on a weekly basis.

Fig. 1 Schematic representation of experimental setup. Key: (1) rotameter, (2) regulator, (3) oxygen bottle, (4) microcosm reactor, (5) leachate holding tank, (6) oxygen absorption bottle,

(7) orsat gas analyzer,

(8) pump, (9) filter,

(10) compressor,

(11) condenser,

(12) refrigerated nutrient tank, (13) solenoid valve,

(14) pressure gauge,

(15) digital multimeter,

(16) delay timer,

(17) programmable timer, and (18) electrical switch

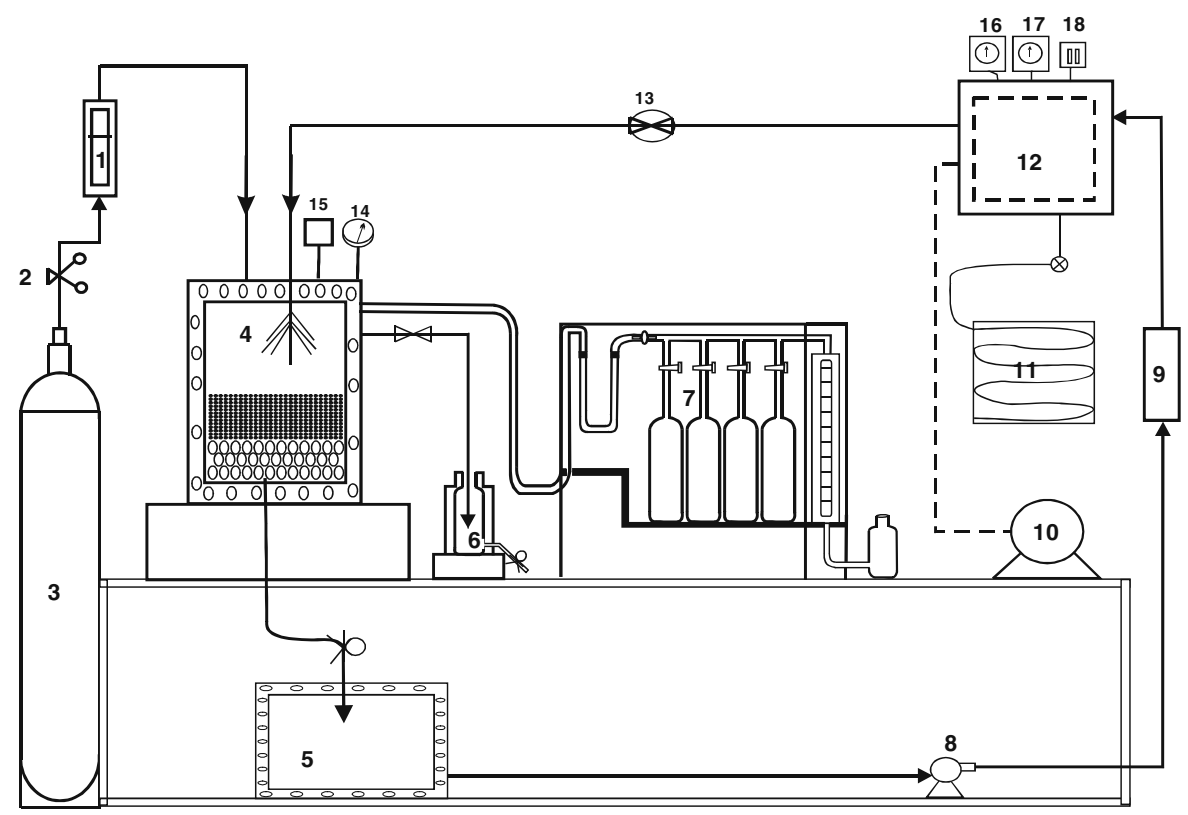


The gas chromatography is equipped with flame ionization detector, and nitrogen was used as a carrier gas at a pressure of $60-65 \mathrm{psi}$. The injector and detector temperatures were $250^{\circ} \mathrm{C}$ and $320^{\circ} \mathrm{C}$, respectively. The column temperature was $40-300^{\circ} \mathrm{C}$ programmed at $10^{\circ} \mathrm{C} / \mathrm{min}$ with computer interphase and a ChemStation software.

\section{Unsteady-state model}

Naphthalene and anthracene transport through a saturated and homogeneous porous media in onedimensional uniform flow considering convection, dispersion, linear equilibrium sorption, and firstorder degradation has been described in our earlier paper (Owabor et al. 2003). The unsteadystate models characterizing the reactions in both macroporous and microporous systems are intended to predict the concentration in the axial $(z)$ and radial $(r)$ directions using the experimental data from a soil microcosm reactor. The summary of the equations is given below.

a. Macroporous system

$$
\begin{aligned}
\frac{\partial C_{i}}{\partial t}= & D \frac{\partial^{2} C_{i}}{\partial z^{2}}-\frac{V}{\varepsilon_{b}} \frac{\partial C_{1}}{\partial z} \\
& -\left(\frac{1-\varepsilon_{b}}{\varepsilon_{b}}\right)\left(\frac{3}{R}\right) k_{f} C_{i}
\end{aligned}
$$

The initial and boundary conditions are:

1. $C_{i}=$ Coi at $t \leq 0, \quad z_{T} \geq z \geq 0$

2. Inlet condition $(z=0, t \leq 0)$ :

$$
C_{o i}+D \frac{\partial C_{i}}{\partial z}=C_{i}
$$

3. Outlet condition $\left(z=z_{T}, t>0\right)$ :

$$
\left.\frac{\partial C_{i}}{\partial z}\right|_{z=z_{T}}=0
$$

b. Microporous system:

$$
\frac{\varepsilon_{p}}{r^{2}} \frac{\partial}{\partial r}\left(r^{2} D_{p i} \frac{\partial C_{s i}}{\partial r}\right)+k_{f}\left(C_{p i}-C_{s i}\right)+R=\frac{\partial C_{s i}}{\partial t}
$$

The initial and boundary conditions are:

1. $C_{s i}(r, t)=C_{s i}(r)$

2. $t \leq 0,0 \leq r \leq R$

3. $\left.\quad \frac{\partial C_{s i}}{\partial r}\right|_{r=R}=0 \quad 0 \leq r \leq R, t \geq 0$

The modeling equations contain the constant transport parameters $V, D, D_{f}, k_{f}$, and $D_{p i}$ required for the simulation of the biodegradation process. These parameters are estimated independently in order to reduce the dimensionality of the search process. The $V$ and $D$ for the nonreactive solute (surfactant) were obtained using the temporal moment solutions of Das and Kluitenberg (1996) and the curve-fitting program CXTFIT described by Toride et al. (1995).

The pore water velocity $(V)$ and dispersion coefficient $(D)$ are estimated in order to calculate the retardation factor $R$ and first-order degradation rate constant $\lambda$.

$V=\frac{x}{\mu_{1}-0.5 t_{0}}$

and

$$
D=\frac{V^{3}}{2 x}\left(\mu_{2}-\mu_{1}^{2}-\frac{t_{0}^{2}}{12}\right)
$$

The film mass transfer coefficient $k_{f}$ was determined from the experimental data on adsorption/desorption, using the relationship of Parvatiyar (1992) cited and reported by Tabak and Govind (1997).

$k_{f}=0.32 \frac{D_{p i}^{2 / 3}}{D_{T}} V^{1 / 3} \operatorname{Re}_{d p}^{3 / 4}\left(\frac{D_{s}^{1 / 2} d_{p}^{-3 / 4}}{D_{T}^{1 / 2} H_{L}^{1 / 4}}\right)$

The pore diffusivities may also be estimated from the expression given by Perry and Green (1998).

$$
D_{p i}=\frac{\varepsilon_{p}}{\bar{T}}\left[\frac{3}{4 \bar{r}}\left(\frac{\pi M}{2 R \theta_{A}}\right)^{1 / 2}+\frac{1}{D_{f}}\right]^{-1}
$$

Where the fluid-phase diffusivity $D_{f}$ may be obtained from the correlation of Wilke and Chang, reported by Bird et al. (2005):

$$
D_{f}=7.4 \times 10^{-8} \frac{\sqrt{\psi_{B} M_{B} T}}{\mu V_{A}^{0.6}}
$$


The solutions of the degradation rate constant $(\lambda)$ and retardation factor $(R)$ were obtained using the expressions of Pang et al. (2003).

$$
\begin{aligned}
& R=\frac{\left(\mu_{1}-0.5 t_{o}\right) \sqrt{V^{2}+4 D \lambda}}{x} \\
& \lambda=\frac{V^{2}}{4 D}\left[\left(1-\frac{2 D}{x V} \operatorname{In} \frac{M_{o}}{C_{o} t_{o}}\right)^{2}-1\right]
\end{aligned}
$$

The $n$th temporal moment of a concentration distribution at a location $x$ was defined by Kucera (1965) and Valocchi (1985) reported and cited by Pang et al. (2003)

$$
M_{n}=\int_{0}^{\infty} t^{n} C(x, t) d t
$$

the $n$th normalized moment of the distribution was defined as

$$
\mu_{n}=\frac{M_{n}}{M_{o}}=\frac{\int_{0}^{\infty} t^{n} C(x, t) d t}{\int_{0}^{\infty} C(x, t) d t}
$$

Equations 10 and 11 may be used to obtain experimental temporal moments from concentration breakthrough curves.

\section{Breakthrough curves}

The experimental breakthrough data for the tracer, naphthalene, and anthracene from a soil microcosm reactor are plotted in Figs. 2, 3, and 4.

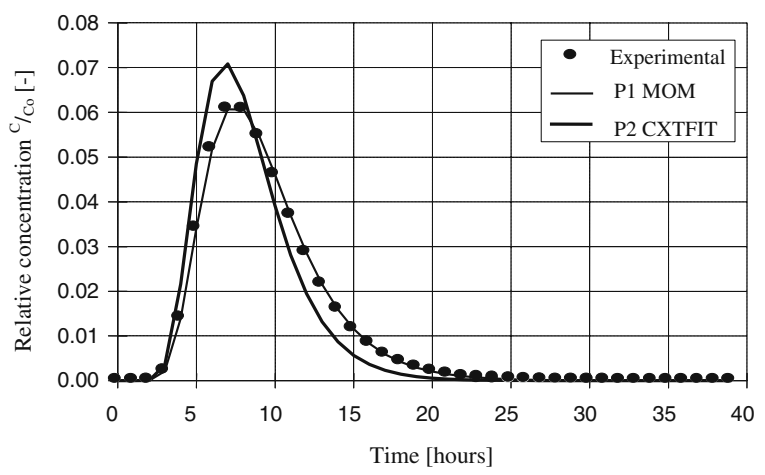

Fig. 2 Comparison of MOM AND CXTFIT simulated breakthrough curves for tracer using experimental data

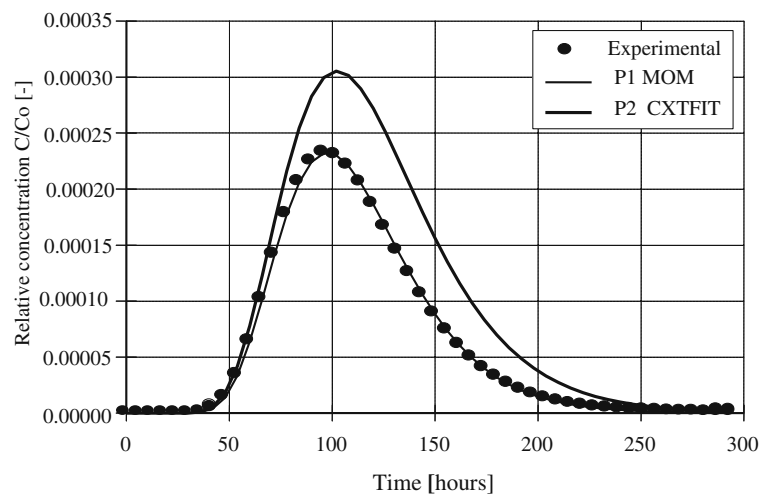

Fig. 3 Comparison of MOM and CXTFIT simulated breakthrough curve for naphthalene using experimental data

In these figures, the dimensionless concentration of tracer and total polycyclic aromatic hydrocarbons is plotted against time. For 40-h duration, an initial low level of normalized concentration characterized the plots $C / C_{0}$. The breakthrough data were simulated from solutions of two analytical transport models: the nonlinear least square curve-fitting CXTFIT program and the temporal moment solutions (MOM).

By using experimental data from a sandy soil microcosm reactor, the CXTFIT curve-fitting program and the temporal moment solution were applied in the estimation of the transport parameters $V$ (pore water velocity) and $D$ (dispersion coefficient), for the tracer (nonreactive solute) which

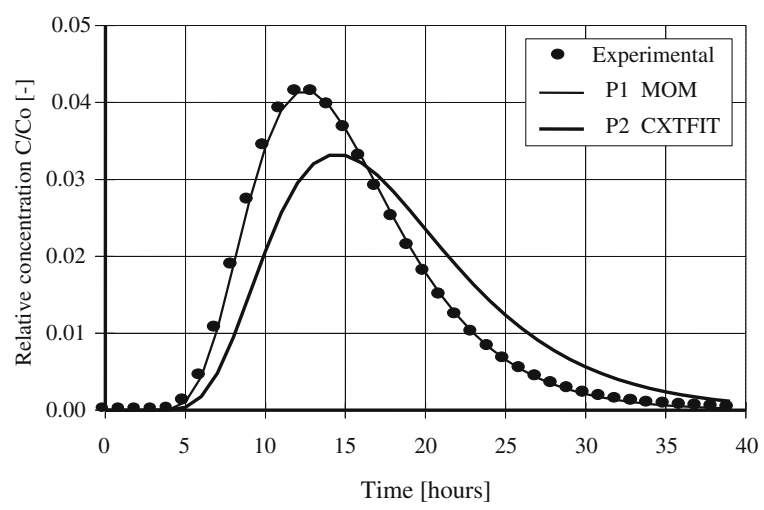

Fig. 4 Comparison of MOM and CXTFIT simulated breakthrough curve for anthracene using experimental data 
Table 1 Pore water velocity and dispersion coefficient obtained from methods of temporal moments and CXTFIT curvefitting program

\begin{tabular}{|c|c|c|c|c|c|c|}
\hline \multirow[t]{2}{*}{ Tracer } & \multicolumn{3}{|c|}{$\mathrm{V}$ (m/day) } & \multicolumn{3}{|c|}{$\mathrm{D}\left(\mathrm{m}^{2} /\right.$ day $)$} \\
\hline & $\overline{\mathrm{MOM}}$ & CXTFIT & $\varepsilon$ & $\overline{\mathrm{MOM}}$ & CXTFIT & $\varepsilon$ \\
\hline Sodium hexametaphosphate & 2.15 & 2.24 & -0.04 & 2.79 & 2.47 & 0.11 \\
\hline
\end{tabular}

serves to characterize the advection and dispersion, the first-order degradation rate constant $\lambda$ and the retardation factor $R$ for naphthalene and anthracene. The summary of the results is given in Tables 1 and 2. The retardation factor is a dimensionless parameter which describes the bioavailability of naphthalene relative to anthracene, and it increases with increasing solute hydrophobicity.

\section{Method of solution}

The backward finite difference scheme was employed in the resolution of the second-order partial differential equations for the macroporous and microporous systems. Both terms on the righthand side and left-hand side of Eqs. 1 and 2 have the unit of concentration. The scheme involves the discretization of both depth $(Z)$ and time $(t)$ simultaneously into mesh or grid points with constant intervals.

The $z-t$ plane is subdivided into equal time steps $\Delta \tau=k$ and depth step $\Delta z=h$. The representative mesh point $p$ is $z=i h$ and $\tau=j k$ where $i, j=0,1,2,3, \ldots \ldots N$.

Thus

$C_{p}=C(i h, j k)=C_{i, j}$

The backward finite difference scheme is valid and converges for all values of $k / h^{2}$, i.e., $k / h^{2} \geq$ 0 . This is known as the stability criterion. To allow for more flexibility of the result to the equations, some dimensionless variables given by Eqs. 12 to 20 are defined

$$
\begin{aligned}
z & =\frac{Z_{T}}{L} \Rightarrow \frac{\partial z}{\partial Z_{T}}=\frac{1}{L} \\
\tau & =\frac{t}{T}
\end{aligned}
$$

$$
\bar{C}=\frac{C}{C_{O}}
$$

$C_{O}=100$

$\frac{\partial \bar{C}}{\partial C}=\frac{1}{C_{O}}$

also,

$\frac{\partial^{2} \bar{C}}{\partial^{2} C}=\frac{1}{C_{O}}$

$C_{O} \frac{\partial \bar{C}}{\partial \tau}=C_{O} \frac{\partial^{2} \bar{C}}{\partial z^{2}}$

$\frac{\partial \bar{C}}{\partial \tau}=\frac{\partial^{2} \bar{C}}{\partial z^{2}}$

$C_{O} \frac{\partial \bar{C}}{\partial \tau}=C_{O} \frac{\partial^{2} \bar{C}}{\partial r^{2}}$

$\frac{\partial \bar{C}}{\partial \tau}=\frac{\partial^{2} \bar{C}}{\partial r^{2}}$

\begin{tabular}{|c|c|c|c|c|c|c|}
\hline \multirow[t]{2}{*}{ PAHs } & \multicolumn{3}{|l|}{$R$} & \multicolumn{3}{|c|}{$\lambda$ (per day) } \\
\hline & MOM & CXTFIT & $\varepsilon$ & MOM & CXTFIT & $\varepsilon$ \\
\hline Naphthalene & 25.77 & 20.23 & 0.21 & 3.54 & 4.22 & -0.19 \\
\hline Anthracene & 41.62 & 28.43 & 0.32 & 1.21 & 2.05 & -0.69 \\
\hline
\end{tabular}

Table 2 Degradation parameters for naphthalene and anthracene from experimental data

Where $\varepsilon=\frac{\text { MOM }_{\text {value }}-\text { CXTFIT }_{\text {value }}}{\text { MOM }_{\text {value }}}$ 
Nondimensionalizing Eqs. 1 and 2, we have

$$
\begin{aligned}
& \frac{\partial \bar{C}}{\partial \tau}=\alpha \frac{\partial^{2} \bar{C}}{\partial z^{2}}-\beta \frac{\partial \bar{C}}{\partial z}-\gamma\left(\bar{C}_{i}\right)=1 \\
& \psi \frac{\partial \bar{C}}{\partial \tau}=\frac{\partial^{2} \bar{C}}{\partial r^{2}}+\frac{\partial \bar{C}}{\partial r}-\eta \bar{C}+\phi=1
\end{aligned}
$$

where

$\alpha=D, \beta=\frac{V}{\varepsilon_{b}}, \gamma=\left(\frac{1-\varepsilon_{b}}{\varepsilon_{b}}\right) \frac{3}{R} k_{f}$

$\eta=\frac{k}{\alpha}, \quad \psi=\frac{1}{\alpha}, \quad \phi=\frac{R+k C_{p}}{\alpha}$

subject to

$$
\begin{aligned}
& \bar{C}=\bar{C}_{O 1}^{-} 1>z>0, \tau=0 \\
& \bar{C}(z, 0)=1, \tau=0 \\
& \bar{C}=\bar{C}_{O 1}^{-} 1>r>0, \tau=0 \\
& \bar{C}(r, 0)=1, \quad \tau=0
\end{aligned}
$$

Discretizing Eq. 1, we get

$C=C_{i, j}$

$\frac{\partial C}{\partial z}=\frac{C_{i+1, j}-C_{i, j}}{h}$

$\frac{\partial^{2} C}{\partial z^{2}}=\frac{C_{i-1, j+1}-2 C_{i, j+1}+C_{i+1, j+1}}{h^{2}}$

$\frac{\partial C}{\partial t}=\frac{C_{i, j+1}-C_{i, j}}{k}$

with $h=0.015, k=7$

Substituting Eqs. 29 to 32 and values of $\alpha, \beta$, $\gamma$, and $\bar{C}$ into the nondimensionalized Eq. 21, we have

$$
\begin{aligned}
C_{i-1, j+1} & -2 C_{i, j+1}+C_{i+1, j+1} \\
= & -2.49 \mathrm{E}-3 C_{i, j}+1.49 \mathrm{E}-3 C_{i+1, j}
\end{aligned}
$$

Similarly, discretizing Eq. $2 \Rightarrow$

$C=C_{i, j}$

$\frac{\partial C}{\partial r}=\frac{C_{i+1, j}-C_{i, j}}{h}$

$\frac{\partial^{2} C}{\partial r^{2}}=\frac{C_{i-1, j+1}-2 C_{i, j+1}+C_{i+1, j+1}}{h^{2}}$

$\frac{\partial C}{\partial t}=\frac{C_{i, j+1}-C_{i, j}}{k}$

with $h=0.001, k=7$
Equation 2 is similarly treated following the procedure of treating Eq. 1. Hence, we have:

$$
\begin{aligned}
C_{i-1, j+1} & -3.4 C_{i, j+1}+C_{i+1, j+1} \\
& =-1.18 C_{i, j}-0.2 C_{i+1, j}-0.74
\end{aligned}
$$

Equations 33 and 38 are the iterative forms of the unsteady-state model equations for the macroporous and microporous systems. By applying the corresponding boundary conditions, nine equations result with nine unknowns, which can be evaluated simultaneously. The simultaneous equations were resolved using the inverse matrix method. To ease the computation of the solution, the Microsoft Excel program was applied.

The retardation factor $(R)$ and first-order degradation rate constant $(\lambda)$ for naphthalene and anthracene were estimated by setting the experimentally determined moments equal to the theoretical moments as reported by Das and Kluitenberg (1996). In addition, the experimental data were also fitted to the analytical solutions of a transport model CXTFIT curve fitting described by Toride et al. (1995). The method of temporal moments (MOM) was determined from the experimental data using the trapezoidal rule of the normalized concentration-time plot. The theoretical moments from the model were derived using a Laplace-transformed version of the model described by previous investigator Pang et al. (2003).

\section{Results}

Modeling results

The independent estimation of the constant transport parameters $D_{f}, k_{f}$, and $D_{p i}$ resulted in the reduction of the dimensionality of the search process of the unsteady-state model. The estimated values of these parameters for naphthalene and anthracene are shown in Table 3. The film

Table 3 Estimated values of the parameters for the solution of the modeling equations

\begin{tabular}{llll}
\hline Contaminants & $k_{f}(\mathrm{~m} /$ day $)$ & $D_{p i}\left(\mathrm{~m}^{2} /\right.$ day $)$ & $D_{f}\left(\mathrm{~m}^{2} /\right.$ day $)$ \\
\hline Naphthalene & $1.924 \mathrm{E}-3$ & $8.61 \mathrm{E}-6$ & $7.28 \mathrm{E}-5$ \\
Anthracene & $1.72 \mathrm{E}-3$ & $8.59 \mathrm{E}-6$ & $6.10 \mathrm{E}-5$ \\
\hline
\end{tabular}


Fig. 5 Variation of concentration of naphthalene with time and depth of soil particle

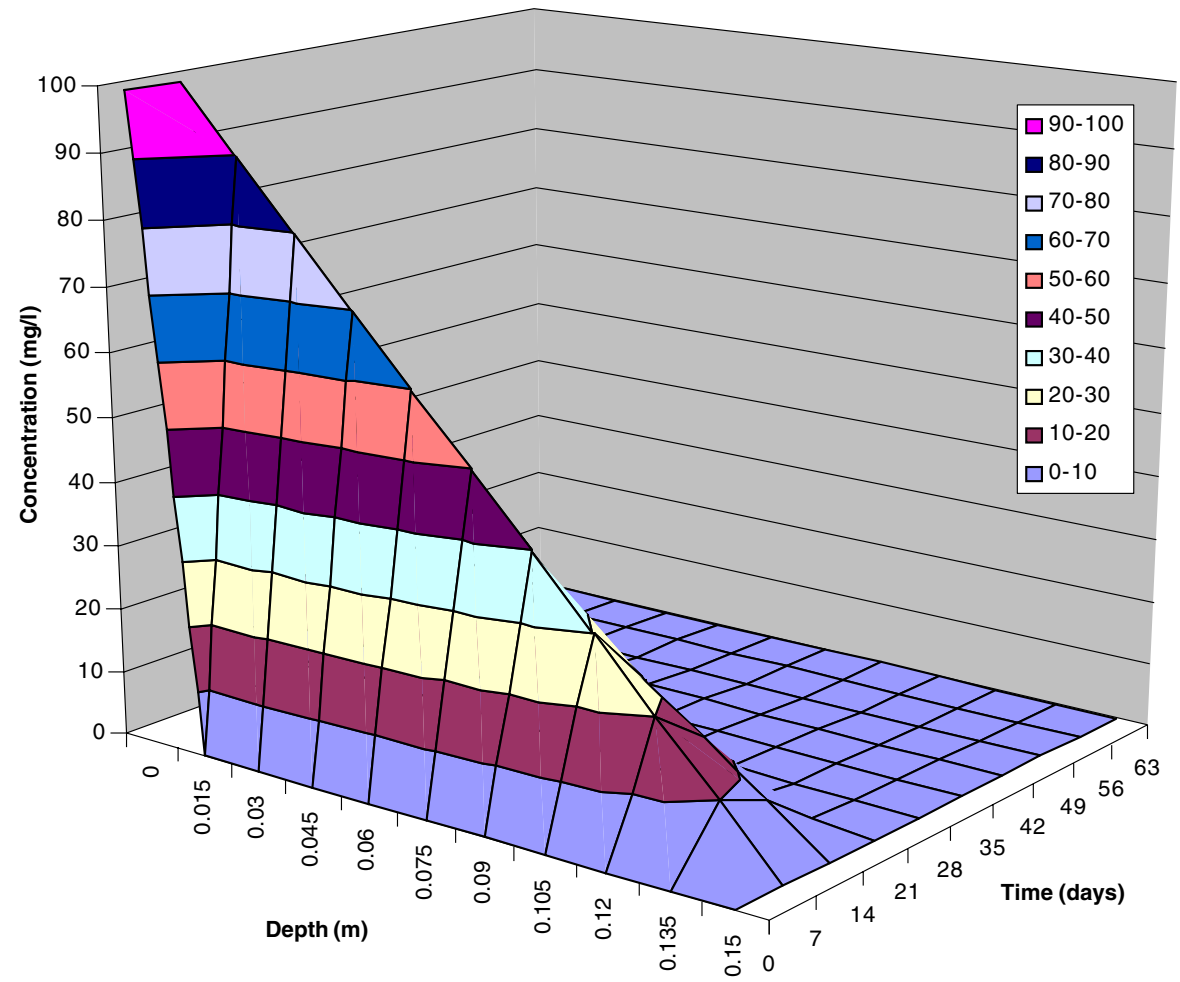

mass transfer coefficient $k_{f}$ represents the resistance to mass transfer between the fluid phase and solid phase. The values depict that the re-

sistance to transfer for anthracene is predominant. The pore diffusivities are indicative of a slow diffusive mechanism for anthracene. The
Fig. 6 Variation of concentration of anthracene with time and depth

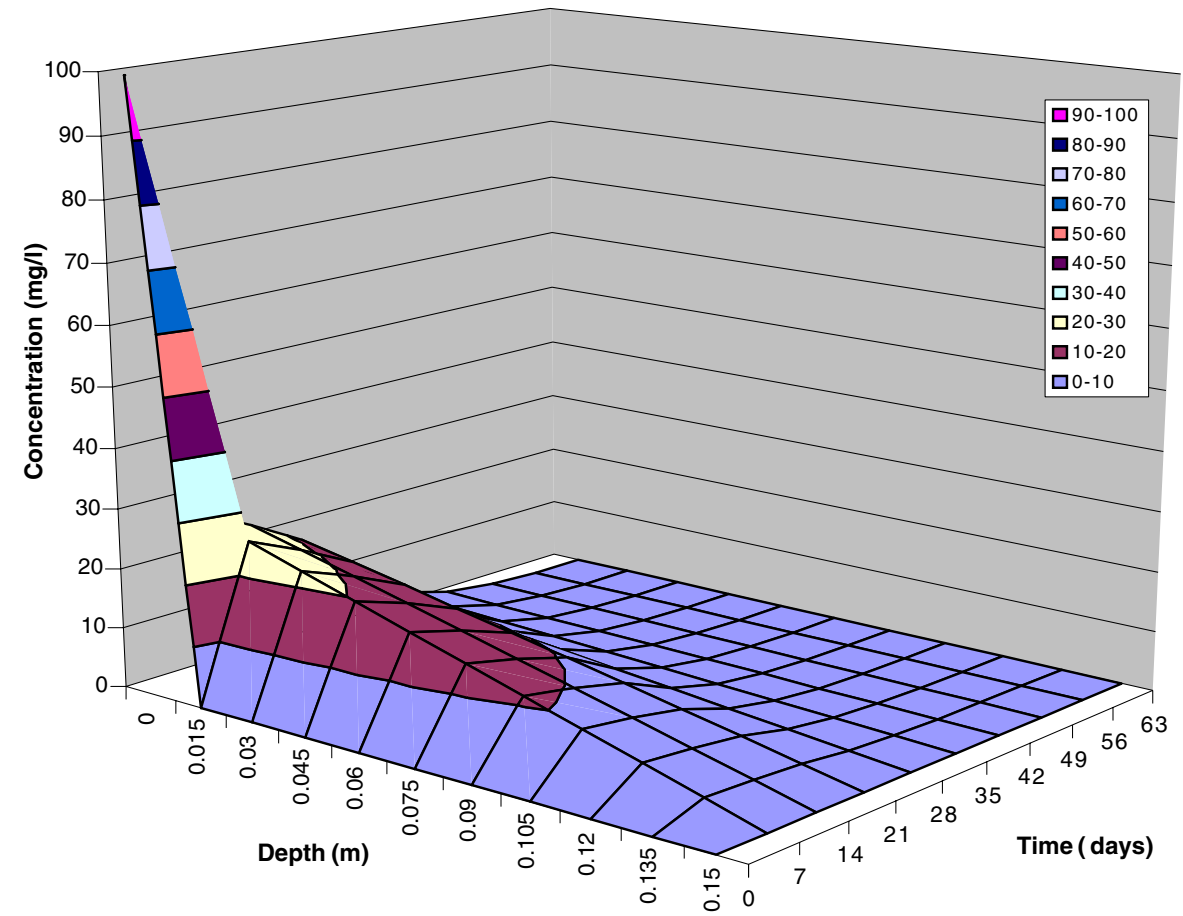


Fig. 7 Variation of concentration of naphthalene with time and radius of soil particle

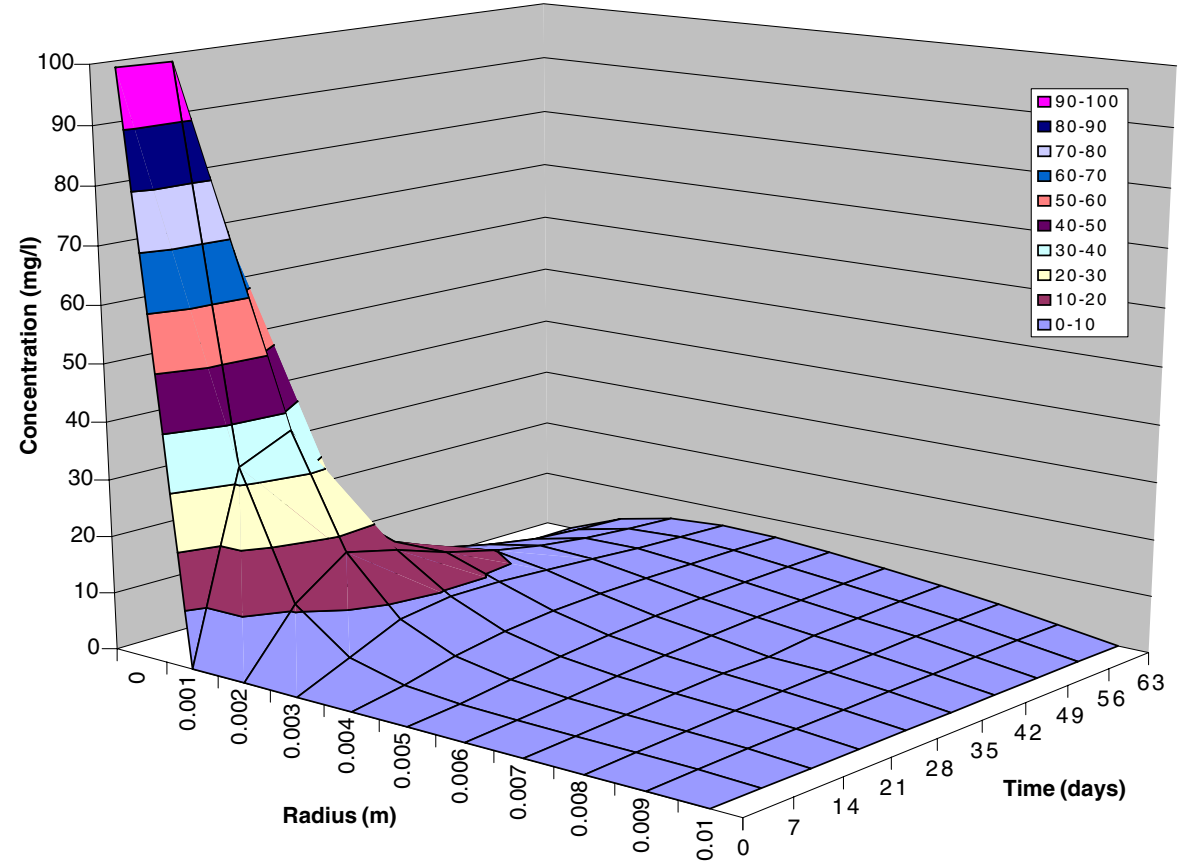

results of the modeling equations which describe the one-dimensional convective-dispersive solute transport with linear equilibrium sorption and degradation for the macroporous and mi- croporous systems are shown using the threedimensional plots of Figs. 5, 6, 7, and 8 .

The profiles show the surface concentration with time for naphthalene and anthracene in both
Fig. 8 Variation of concentration of anthracene with time and radius of soil particle

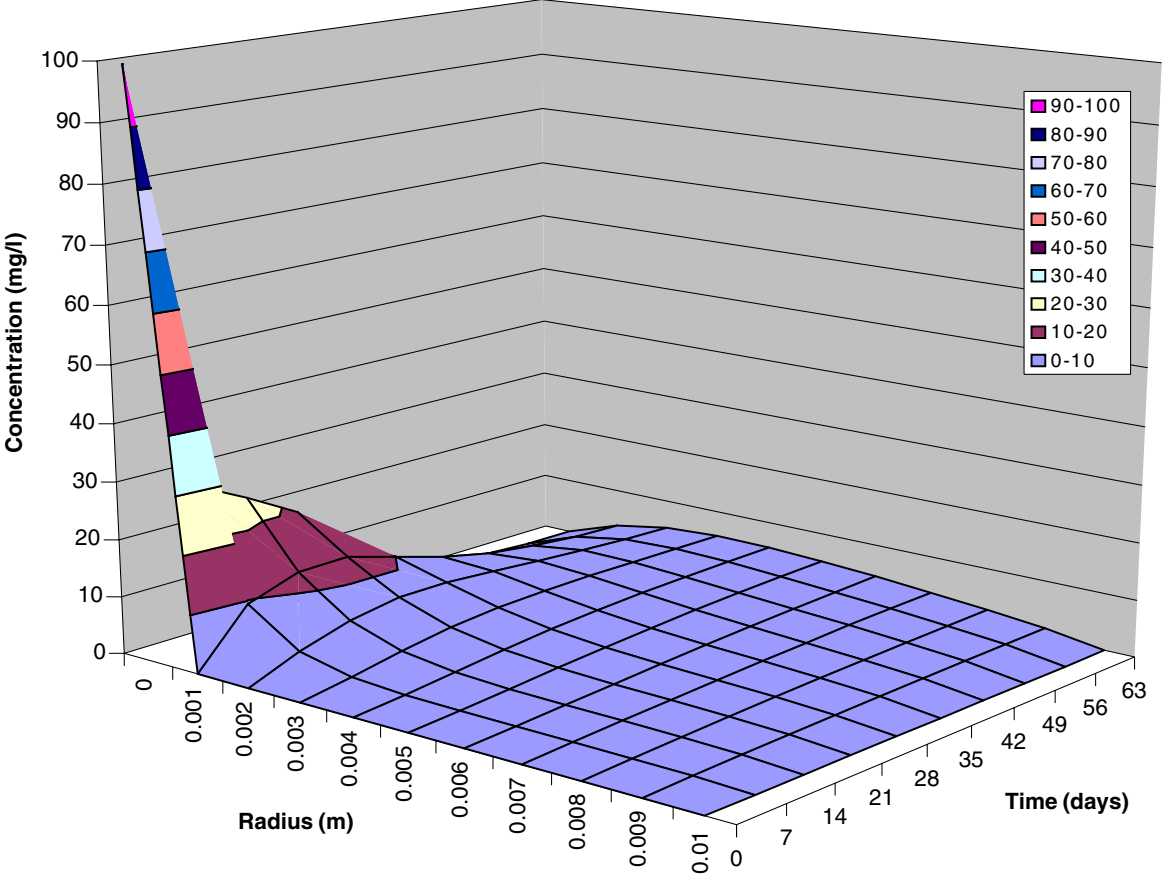


Table 4 Residual concentration of naphthalene and anthracene in both axial and radial directions

\begin{tabular}{lll}
\hline PAHs & Axial $(\mathrm{mg} / \mathrm{l})$ & Radial $(\mathrm{mg} / \mathrm{l})$ \\
\hline Naphthalene & $1.116 \mathrm{E}-5$ & 1.478 \\
Anthracene & $7.67 \mathrm{E}-4$ & 1.609 \\
\hline
\end{tabular}

axial and radial directions. Residual concentrations of the two polycyclic aromatics are shown in Table 4. From the table of results, the presence of the aromatics is more pronounced in the micropores of the soil particle. The summarized simulated results showed that the decay rate was faster in the macroporous system than in the microporous system and that the concentration of naphthalene was lower in both systems.

\section{Discussion}

The predicted breakthrough profiles for tracer, naphthalene, and anthracene shown in Figs. 2-4 using both the CXTFIT curve-fitting program and the temporal moment solution (MOM) exhibited good agreement. The comparative analysis of the concentration breakthrough curves in the contaminant transport studies for nonreactive solute (tracer) and the experimental PAHs using the MOM and CXTFIT, presented in the profiles of Figs. 2-4, showed that they both fit the experimental breakthrough curve, although the MOM had a better fit. This was because, with MOM, no assumptions about the initial conditions for the experiment were required. An experimental breakthrough time of $5 \mathrm{~h}$ for tracer and $17 \mathrm{~h}$ for anthracene was observed. Naphthalene was completely zero. This behavior displayed by naphthalene may be attributable to its very high diffusive mechanism through the liquid phase to solid phase. The period of low concentration is characterized by effective adsorption of the chemicals onto the surface of the soil particles. The micropores and submicropores of the soil particle present a large quantity of adsorption sites ultimately leading to high adsorption rate. This phenomenon is followed by a sharp reduction in adsorption as indicated by the ascent of the normalized concentration profiles presented in Figs. 2-4. The reduc- tion in adsorption may be due to the fact that most of the pores or sites for adsorption have become filled. These results suggest that anthracene will elute after the breakthrough of naphthalene and the tracer. Results are shown in Tables 1 and 2 . It was observed that the coefficient of deviation $\varepsilon$ values for $V$ was one order of magnitude less than the value of $D, R$, and $\lambda$. The reason can be attributed to the fact that only the first normalized moment is required to estimate $V$ for a nonreactive solute. Estimation of $D, R$, and $\lambda$ required both first and second normalized moments, which resulted in the observed marked deviation. This observation was found to be consistent with the reports of Leij and Dane (1992) and Pang et al. (1998) as cited by Pang et al. (2003) where it was noted that the higher the orders of the moments are, the less stable is the calculation. The MOM estimates higher values of $R$ and $D$ when compared with the least squares curve-fitting program. The argument is that, since the MOM estimate is a function of the difference between the second moment and the first moment squared, small concentrations that are measured at times distant from the first moment (i.e., BTC tail) will have a great influence on the estimates. Conversely, CXTFIT curve-fitting program results are based on minimizing the sum of the squares deviation, and the high-concentration data points dominate these. The results thus show that the first moment calculation is positively influenced by calculation in the BTC tail and that the MOM does better fitting of the tails.

The numerical simulation, given the initial and boundary conditions on the one hand, showed a progressive decrease in the concentration of naphthalene and anthracene with time in the axial direction, while on the other hand, it showed that with increasing contact time, more of the aromatics were found within the soil particle pores. As shown in Table 4, the residual concentrations obtained indicate that biodegradation of these contaminants occur on the soil particle surface, and these results further affirmed the fact that the microbial utilization of anthracene for metabolic activities was greatly limited by its resistance to mass transfer between the fluid phase and the soil matrix occasioned by its low aqueous solubility. 


\section{Conclusion}

The temporal moment solutions were satisfactorily verified in this study using breakthrough data obtained from a soil microcosm experiment. The agreement achieved between the theoretical predictions is clearly indicated by the experimental breakthrough time. Anthracene was found to elute after the breakthrough of naphthalene. The efficiency of the unsteady-state model for macroporous and microporous systems is shown in the residual concentration predicted for the contaminant aromatics.

\section{Nomenclature}

\section{$V \quad$ Pore water velocity (m/day)}

$V_{A} \quad$ Molar volume of pure solute as liquid at its normal boiling point $\left(\mathrm{m}^{3} / \mathrm{gmol}\right)$

$D \quad$ Dispersion coefficient $\left(\mathrm{m}^{2} /\right.$ day $)$

$k_{f} \quad$ Mass transfer coefficient for external film diffusion $(\mathrm{cm} / \mathrm{h})$

$D_{p i} \quad$ Pore diffusivity $\left(\mathrm{m}^{2} /\right.$ day $)$

$D_{f} \quad$ Diffusivity of the fluid phase $\left(\mathrm{m}^{2} /\right.$ day)

$C_{o} \quad$ Initial concentration at time $=0(\mathrm{mg} / \mathrm{l})$

$C_{i} \quad$ Concentration of contaminant in the external pellet surface, i.e., opening of the pores $(\mathrm{mg} / \mathrm{l})$

$C_{s i} \quad$ Concentration of contaminant in the solid phase (mg/l)

$C_{p i} \quad$ Concentration of contaminant in the fluid phase within the pore of soil particle $(\mathrm{mg} / \mathrm{l})$

$\varepsilon_{\mathrm{b}} \quad$ Porosity of soil

$\varepsilon_{\mathrm{p}} \quad$ Internal porosity of soil particle

$r \quad$ Distance from the center of the particle $(\mathrm{cm})$

$R \quad$ Radius of soil particle $(\mathrm{cm})$

$Z \quad$ Axial distance $(\mathrm{cm})$

$t \quad$ Exposure (contact) time between chemical and soil sediment (days)

$t_{0} \quad$ Time of instantaneous injection of sorbing solutes (s)

$x \quad$ Distance in the direction of concentration distribution $(\mathrm{cm})$

$\lambda \quad$ First-order degradation rate $\left(\mathrm{min}^{-1}\right)$

$R \quad$ Retardation factor

$\geq \quad$ Coefficient of deviation

$\bar{d}_{\mathrm{p}} \quad$ Average soil particle diameter $(\mathrm{cm})$
$H_{\mathrm{L}} \quad$ Height of liquid in the reactor $(\mathrm{cm})$

$\bar{r} \quad$ Average pore radius (cm)

$\mu \quad$ Viscosity of the solution (cp)

$\psi_{B} \quad$ "Association parameter" for the solvent

$M_{B} \quad$ Molecular weight of pure solute

$\theta_{A} \quad$ Absolute temperature (K)

$R \quad$ Molar gas constant

$T \quad$ Absolute temperature (K)

$\bar{T} \quad$ Tortuosity (usually between 2 and 6)

$D_{T} \quad$ Reactor diameter $(\mathrm{cm})$

$D_{s} \quad$ Impeller diameter $(\mathrm{cm})$

RRE Relative error

\section{Dimensionless parameters}

$\begin{array}{ll}\tau=t / T & \text { Dimensionless time } \\ C=C_{i} / C_{o i} \text { or } c_{s i} / c_{o i} & \begin{array}{l}\text { Dimensionless concentra- } \\ \text { tion }\end{array} \\ \alpha, \beta, \gamma & \text { Constants defined by Eq.23 } \\ \psi, \eta, \varphi & \text { Constants defined by Eq.24 } \\ Z=z_{T} / z & \text { Dimensionless depth } \\ \mu_{1} \text { and } \mu_{2} & \text { First and second temporal } \\ & \text { moments } \\ \mu_{n} & n \text {th normalized moment of } \\ & \text { a distribution } \\ M_{n} & n \text {th temporal moment of a } \\ & \text { concentration distribution } \\ M_{o} & \text { Theoretical zeroth tempo- } \\ & \text { ral moment of a concentra- } \\ & \text { tion distribution } \\ \operatorname{Re}_{d p} & \text { Reynold's number of com- } \\ & \text { ponent }\end{array}$

Open Access This article is distributed under the terms of the Creative Commons Attribution Noncommercial License which permits any noncommercial use, distribution, and reproduction in any medium, provided the original author(s) and source are credited.

\section{References}

Bird, R. B., Stewart, W. E., \& Lightfoot, E. N. (2005). Transport phenomena (2nd ed., pp. 528-530). Hoboken: Wiley.

Chung, W. K., \& King, G. M. (2001). Isolation, characterization and polyaromatic hydrocarbon degradation potential of aerobic bacteria from marine macrofaunal burrow sediments. Applied and Environmental Microbiology, 67(11), 5585-5592. 
Das, B. S., \& Kluitenberg, G. J. (1996). Moment analysis to estimate degradation rate constants from leaching experiments. American Journal of Soil Science, 60, 1724-1731.

Gamerdinger, A. P., Achin, R. S., \& Traxler, R. W. (1997). Acifluorfen sorption, degradation and mobility in a Mississippi Delta soil. Soil Science Society of America Journal, 64, 112-121.

Janikowski, T., Velicogna, D., Punt, M., \& Daugulis, A. (2004). Use of a two-phase partitioning bioreactor for degrading polycyclic aromatic hydrocarbons by a Sphingomonas spp. Applied Microbiology and Biotechnology, 59, 2-3.

Guo, L., \& Wagenet, R. J. (1999). Evaluation of alachlor degradation under transport conditions. Soil Science Society of America Journal, 63, 747-755.

Oboh, B. O., Ilori, M. O., Akinyemi, J. O., \& Adebusoye, S. A. (2006). Hydrocarbon degrading potentials of bacteria isolated from a Nigerian bitumen (Tarsand) deposit. Nature and Science, 4(2), 51-57.

Okerentugba, P. O., \& Ezeronye, O. U. (2003). Petroleum degrading potential of single and mixed microbial cultures isolated from rivers and refinery effluent in Nigeria. African Journal of Biotechnology, 2, 288-292.

Owabor, C. N., Ogbeide, S. E., \& Susu, A. A. (2003). Substrate biodegradation in contaminated aqueoussoil matrix. Model development for macroporous and microporous systems. Journal of Science Technology \& Environment, 3(1-2), 36-41.

Pang, L., Close, M. E., \& Noonan, M. (1998). Rhodamine WT and Bacillus subtilis transport through an alluvial gravel aquifer. Groundwater, 36(1), 112-122.

Pang, L., Gottz, M., \& Close, M. (2003). Application of the method of temporal moments to interpret solute transport with sorption and degradation. Journal of Contaminated Hydrology, 60, 123-134.

Perry, R. H., \& Green, D. W. (1998). Perry's chemical engineers handbook (7th ed.). Singapore: McGraw Hill Book.

Reardon, K. F., Mosteller, D. C., Rogers, J. B., Duteau, N., \& Kim, K. (2002). Biodegradation kinetics of aromatic hydrocarbon mixtures by pure and mixed bacterial cultures. Environmental Health Perspectives, 110, 1005-1011.

Sudarat, B., Britz, M. L., \& Grant, A. S. (2000). Degradation and mineralization of high molecular-weight polycyclic aromatic hydrocarbons by defined fungalbacterial cocultures. Applied and Environmental Microbiology, 66(2), 1007-1019.

Tabak, H. H., \& Govind, R. (1997). Bioavailability and biodegradation kinetics protocol for organic pollutant compounds to achieve environmentally acceptable endpoints during bioremediation. In R. K., Baipai \& M. E. Zappi (Eds.), Bioremediation of surface and subsurface contamination. Annals of the New York Academy of Sciences (Vol. 829, pp. 36-61).

Toride, N., Leij, F. J., \& Van Genuchten, M. T. (1995). The CXTFIT code for estimating transport parameters from laboratory or field version 2.0. US Dep. Agric., Res. Rep. No. 138, 121.

Vanderborght, J., Timmerman, A., \& Feyen, J. (2000). Solute transport for steady-state and transient flow in soils with and without macropores. Soil Science Society of America Journal, 64, 1305-1317.

Zhu, L., Chen, B., \& Tao, S. (2004). Sorption behaviour of polycyclic aromatic hydrocarbons in soil-water system containing non-ionic surfactant. Environmental Engineering Science, 21, 263-272. 